Research Article

\title{
Functionality Analysis of Spent Coffee Ground Extracts Obtained by the Hydrothermal Method
}

\author{
Chin-Tung Wu, ${ }^{1}$ Dinesh Chandra Agrawal $\mathbb{D}^{2},{ }^{2}$ Wen-Ying Huang $\mathbb{D},{ }^{3}$ Hsiu-Cheng Hsu, ${ }^{4}$ \\ Shang-Jhen Yang, ${ }^{5}$ Shu-Ling Huang $\mathbb{D},{ }^{5}$ and Yung-Sheng Lin $\mathbb{D}^{5}$ \\ ${ }^{1}$ Bachelor Program in Interdisciplinary Studies, College of Future, National Yunlin University of Science and Technology, \\ Yunlin, Taiwan \\ ${ }^{2}$ Department of Applied Chemistry, Chaoyang University of Technology, Taichung, Taiwan \\ ${ }^{3}$ Department of Applied Cosmetology, HungKuang University, Taichung, Taiwan \\ ${ }^{4}$ Department of Dermatology, Changhua Christian Hospital, Changhua, Taiwan \\ ${ }^{5}$ Department of Chemical Engineering, National United University, Miaoli, Taiwan
}

Correspondence should be addressed to Dinesh Chandra Agrawal; dc.agrawal99@gmail.com and

Yung-Sheng Lin; linys@nuu.edu.tw

Received 16 May 2019; Revised 13 September 2019; Accepted 25 September 2019; Published 20 November 2019

Academic Editor: Kaustubha Mohanty

Copyright $(2019$ Chin-Tung Wu et al. This is an open access article distributed under the Creative Commons Attribution License, which permits unrestricted use, distribution, and reproduction in any medium, provided the original work is properly cited.

Coffee is a popular beverage all over the world, but spent coffee grounds (SCGs) constituting almost 75\% of original beans are usually considered waste and disposed off. The present study analyzed the functionalities of SCG with a view of its reuse in the cosmetic industry. The SCG extraction was carried out by the hydrothermal method. The resultant extracts were tested for its antioxidant capacity, tyrosinase inhibition, and moisturizing ability. LC-MS/MS results showed two major components in SCG extracts, namely, trigonelline and caffeine. Also, the SCG contained total flavonoid contents of $29 \pm 4.5 \mathrm{mg}$ quercetin equivalents (QE)/g SCG and total phenolic contents of $9.44 \pm 0.90 \mathrm{mg}$ gallic acid equivalents (GAE)/g SCG. Regarding functionality analysis, SCG extracts exhibited reduction capacity of $8.18 \pm 0.39 \mathrm{mg}$ vitamin C equivalent (VCE)/g SCG, DPPH free-radical scavenging activity ( IC $_{50}$ ) of $3.11 \mathrm{mg} \mathrm{SCG} / \mathrm{mL}$, ABTS free-radical scavenging activity $\left(\mathrm{IC}_{50}\right)$ of $13.61 \mathrm{mg} \mathrm{SCG} / \mathrm{mL}$, and tyrosinase inhibition capacity $\left(\mathrm{IC}_{50}\right)$ of $2.23 \mathrm{mg} \mathrm{SCG} / \mathrm{mL}$. Moreover, the volatilization rate of the extract solution $(37 \mathrm{mg} \mathrm{SCG} / \mathrm{mL}$ ) reduced by $15.9 \%$. These results demonstrate the utility of recycling of SCG and illustrate its potential application in the development of skin care products.

\section{Introduction}

Coffee is one of the most popular beverages all over the world, consumed for leisure and boosting energy levels, and is a symbol of personal taste. However, spent coffee grounds (SCGs), the by-product obtained from roasted coffee beans after water extraction, are usually considered waste and are disposed off. The average weight of SCG is about $75 \%$ that of the original coffee bean. According to the coffee trade record from the International Coffee Organization, the total coffee production in 2018 was about 9.5 million metric tons. Moreover, the annual quantity of SCG was about 6 million tons worldwide [1]. In Taiwan alone, the quantity of disposed-off SCG exceeds 30 metric tons per day. Since the disposal of SCG causes environmental pollution, questions have been asked if SCG can be recycled to create new business opportunities. Several researchers have attempted to find answers to these questions. Mussatto and co-workers reported the use of SCG as animal feeds and farm fertilizer [2]. In addition, several other uses such as biofuel [3], its bioconversion to carotenoids and other valuable metabolites [4], and its application in decontamination of water from heavy metal ions [5] have been reported. Due to the presence of chlorogenic acid, SCG has exhibited significant anti-inflammatory and antiallergic activities [6, 7].

SCG predominantly contains polyphenolics, lipids, and lignin. The richness of polyphenolics such as chlorogenic 
acid, caffeic acid, gallic acid, ferulic acid, and cinnamic acid [8] is conducive for the production of high-value-added products, especially for cosmetics and skin care. However, an extraction technique plays a critical role in the recovery of functional compounds from SCG. Conventional methods for SCG extraction like probiotic fermentation, enzymatic hydrolysis, solvent extraction [9], and microwave-assisted extraction [10] have been reported. This study employed the hydrothermal method to extract components of SCG. The hydrothermal method is a pyrolysis treatment. The hightemperature $\left(120-200^{\circ} \mathrm{C}\right)$ and high-pressure water treatment used in this method facilitates the extraction of water-soluble components from SCG, including proteins, minerals, and organic acids. It is similar to brewing a sample of coffee beans for second time. This study employed high-pressure steam for extraction of active ingredients from SCG that had not previously been extracted in coffee brewing processes. The resultant extracts were tested for its antioxidant capacity, tyrosinase inhibition, and moisturizing ability to determine the potential application of SCG in personal care products.

\section{Materials and Methods}

2.1. SCG Extraction by Hydrothermal Method. Samples of SCG were collected from Arabica coffee beans in $85^{\circ} \mathrm{C}$ Bakery Café, Taiwan. Five grams of SCG and $35 \mathrm{~mL}$ of deionized water (DI water) were first added to a Teflon beaker; the beaker was then sealed in a stainless steel sample chamber, placed in an autoclave, and heated at $5^{\circ} \mathrm{C} / \mathrm{min}$ from room temperature to $150^{\circ} \mathrm{C}$. At $150^{\circ} \mathrm{C}$, the temperature was kept constant for 3 hours, and then the sample was cooled naturally to room temperature over 12 hours. Subsequently, the sample was extracted and filtered to obtain the extract solution of SCG. The extract solution was then freeze-dried to obtain SCG extracts.

2.2. LC-MS/MS Analysis. An ultrahigh-performance liquid chromatography Xevo triple quadrupole mass spectrometer (UPLC-Xevo-TQ-MS) and Acquity UPLC BEH C18 $(1.7 \mu \mathrm{m}$, $2.1 \times 100 \mathrm{~mm}^{2}$ ) column were used for analysis. The mobile phase comprised a mixture of a $0.1 \%$ formic acid solution and acetonitrile. The acetonitrile concentration increased from $5 \%$ to $65 \%$ in the first 10 minutes and then to $65 \%$ $100 \%$ in the next 5 minutes. The mobile phase flow rate was $0.35 \mathrm{~mL} / \mathrm{min}$. The UPLC-Xevo-TQ-MS used a positive electrospray ionization source and operated at a $3 \mathrm{kV}$ capillary voltage, $5 \mathrm{~V}$ cone voltage, $350^{\circ} \mathrm{C}$ desolvation temperature, and $0.15 \mathrm{~mL} / \mathrm{min}$ collision gas flow rate.

2.3. Total Flavonoid Content Assay. As reported by Wu et al. [11], the present study used quercetin for comparison in all flavonoid content assays. A $200-\mu \mathrm{L}$ SCG extract, $80 \mu \mathrm{L}$ of $\mathrm{CH}_{3} \mathrm{OH}$, and $100 \mu \mathrm{L}$ of $5 \% \mathrm{NaNO}_{2}$ were added to a small centrifuge tube and allowed to react for 5 minutes before $20 \mu \mathrm{L}$ of $10 \% \mathrm{AlCl}_{3}$ was also added. After 6 minutes, $200 \mu \mathrm{L}$ of $1 \mathrm{~N} \mathrm{NaOH}$ was also added, and the mixture was kept in darkness during its reaction for 1 hour. Subsequently, the mixture's optical absorbance at $510 \mathrm{~nm}$ was measured by the spectrophotometer, and the result was compared with a quercetin standard to determine the total flavonoid content (mg) of quercetin equivalent (QE)/g SCG.

2.4. Total Phenolic Content Assay. As in the method used by Huang et al. [12], the present study first uniformly mixed $200 \mu \mathrm{L}$ of $0.5 \mathrm{~N}$ Folin and Ciocalteu's phenol reagent with $200 \mu \mathrm{L}$ of SCG extract solution by shaking them for 5 minutes. Subsequently, $200 \mu \mathrm{L}$ of $10 \% \mathrm{Na}_{2} \mathrm{CO}_{3}$ and $400 \mu \mathrm{L}$ of DI water were added to the mixture, which was allowed to react in darkness at room temperature for 1 hour before being centrifuged at $3000 \mathrm{rpm}$ for 15 minutes. Optical absorbance at $700 \mathrm{~nm}$ was measured using $100 \mu \mathrm{L}$ of the supernatant; the optical absorbance was then substituted into a gallic acid standard curve to determine the total phenolic content (mg) of gallic acid equivalents (GAE)/g SCG.

2.5. Reduction Capacity Assay. As reported by Adjimani and Asare [13], the present study uniformly mixed $100 \mu \mathrm{L}$ of $0.2 \mathrm{M}$ phosphate-buffered saline (PBS) buffer ( $\mathrm{pH}$ 6.6), $100 \mu \mathrm{L}$ of $1 \% \mathrm{~K}_{3} \mathrm{Fe}(\mathrm{CN})_{6}$, and $200 \mu \mathrm{L}$ of the SCG extract solution. The mixture was placed in a $50^{\circ} \mathrm{C}$ water bath for 20 minutes before being removed from the bath and cooled rapidly for 3 minutes. Then, $100 \mu \mathrm{L}$ of $10 \%$ trichloroacetic acid was added, and the mixture was centrifuged at $3000 \mathrm{rpm}$ for 10 minutes. Subsequently, $400 \mu \mathrm{L}$ of the supernatant was extracted and mixed uniformly with $400 \mu \mathrm{L}$ of DI water and $100 \mu \mathrm{L}$ of $0.1 \% \mathrm{FeCl}_{3}$. This mixture was then allowed to react in darkness for 10 minutes to produce $\mathrm{Fe}_{4}\left[\mathrm{Fe}(\mathrm{CN})_{6}\right]_{3}$. Optical absorbance at $700 \mathrm{~nm}$ was measured; a high optical absorbance reading indicated high reduction capacity. This assay employed vitamin $\mathrm{C}$ as the standard to determine the content of vitamin C equivalent (VCE)/g SCG.

2.6. DPPH Free-Radical Scavenging Activity Assay. As mentioned in the previous reports [14-16], the present study uniformly mixed $50 \mu \mathrm{L}$ of $198 \mu \mathrm{M}$ DPPH ethanol solution and $50 \mu \mathrm{L}$ of the SCG extract solution; the mixture was allowed to react in darkness for 30 minutes. Optical absorbance at $517 \mathrm{~nm}$ was measured using a spectrophotometer; a low optical absorbance reading indicated that the sample had high DPPH free-radical scavenging activity. Vitamin C was used as the standard for comparison with SCG concerning with DPPH free-radical scavenging activity:

DPPH free - radical scavenging activity (\%)

$$
=\left[1-\left(\frac{A_{517} \text { of sample }}{A_{517} \text { of blank }}\right)\right] \times 100 \% \text {. }
$$

2.7. ABTS Free-Radical Scavenging Activity Assay. Following previous methods [14-16], the present study uniformly mixed $250 \mu \mathrm{L}$ of $7 \mathrm{mM}$ ABTS with $250 \mu \mathrm{L}$ of $2.45 \mathrm{mM}$ potassium peroxydisulfate; the mixture was allowed to react at $4^{\circ} \mathrm{C}$ in darkness for 16 hours. 
Subsequently, $180 \mu \mathrm{L}$ of ABTS and $20 \mu \mathrm{L}$ of the SCG extract solution were added, and the mixture was allowed to react in darkness for 10 minutes. Optical absorbance at $734 \mathrm{~nm}$ was measured, and a low optical absorbance reading indicated that the sample had high ABTS freeradical scavenging activity. The assay employed an antioxidant, trolox, as the standard for comparison with SCG concerning with ABTS free-radical scavenging activity:

ABTS free - radical scavenging activity (\%)

$$
=\left[1-\frac{\left(A_{734} \text { of sample }-A_{734} \text { of blank }\right)}{\left(A_{734} \text { of control }-A_{734} \text { of blank }\right)}\right] \times 100 \% .
$$

2.8. Tyrosinase Inhibition Capacity Assay. As per the method used $[14,16]$, the present study first uniformly mixed $20 \mu \mathrm{L}$ of the SCG extract solution, $40 \mu \mathrm{L}$ of $3 \mathrm{mM} \mathrm{L}$-Dopa, $10 \mu \mathrm{L}$ of $200 \mathrm{U}$ tyrosinase, and $130 \mu \mathrm{L}$ of $67 \mathrm{mM} \mathrm{PBS}$; the mixture was placed in a $37^{\circ} \mathrm{C}$ water bath for 15 minutes. Optical absorbance at $475 \mathrm{~nm}$ was measured; a low optical absorbance reading indicated high tyrosinase inhibition capacity. Kojic acid was used as the standard for comparison in this assay:

$$
\begin{aligned}
& \text { tyrosinase inhibition capacity }(\%) \\
& \quad=\left[1-\left(\frac{A_{475} \text { of sample }}{A_{475} \text { of blank }}\right)\right] \times 100 \% .
\end{aligned}
$$

2.9. Moisturizing Ability Assay. According to the approach of measuring moisturizing ability $[14,17]$, the present study separately placed the SCG extract solution, DI water, 5\% glycerine, and $10 \%$ glycerine in $6 \mathrm{~mm}$ sample cells. To compare the substances' volatilization rates, the cells were placed in a chamber with the temperature, and relative humidity maintained at $37^{\circ} \mathrm{C}$ and $60 \%$, respectively; they were then taken out and weighed daily for 8 consecutive days to yield results for the calculation of each sample's average volatilization rate.

\section{Results and Discussion}

3.1. LC-MS/MS Analysis. Figure 1(a) presents the liquid chromatography-tandem mass spectrometry (LC-MS/MS) results of the SCG extracts. This study compared its results for retention time and molecular weight with those of previous studies and identified trigonelline and caffeine as major components at two peaks, namely, 0.91 and 1.07 minutes, respectively. Figures 1(b) and 1(c), respectively, present the mass spectrums of trigonelline and caffeine in the SCG extract solution. Regarding the molecular weights at the two peaks above, the $[\mathrm{M}+\mathrm{H}]^{+}$ions had $\mathrm{m} / z$ of 138 at 0.91 minutes, indicating trigonelline as the major component and $m / z$ of 195 at 1.07 minutes, indicating caffeine as the major component. Trigonelline $(\mathrm{m} / z=137)$ and caffeine $(m / z=194)$ were consistent with a recent report [18].

3.2. Total Flavonoid Content Assay. This assay employed quercetin with various concentrations as standards. Increase in optical absorbance indicated higher total flavonoid content due to increase in concentration. Substituting the optical absorbance readings of SCG samples into the quercetin calibration curve yielded the total flavonoid contents in the SCG extracts (Figure 2). By analyzing the concentrations of the SCG extracts alongside the quercetin concentrations, we calculated the total flavonoid content and obtained an average of $29 \pm 4.5 \mathrm{mg}$ QE/g SCG.

Results in Table 1 show that the total flavonoid content in the SCG obtained using the hydrothermal method in the present study (29 $\pm 4.5 \mathrm{mg} \mathrm{QE} / \mathrm{g} \mathrm{SCG})$ was higher than that obtained by ultrasound-assisted extraction $(5.04 \mathrm{mg} \mathrm{QE} / \mathrm{g}$ SCG) [21], methanol extraction (1.81 mg QE/g SCG) [1], and ethanol extraction (2.11 8.03 mg QE/g SCG) [20]. Moreover, Conde and Mussatto [19] employed the hydrothermal method and achieved total flavonoid contents of $8.29 \mathrm{mg}$ QE/g SCG, indicating that the hydrothermal method is more suitable for total flavonoid content.

3.3. Total Phenolic Content Assay. In this study, gallic acid was used as the standard for this assay. The SCG extract solution increased its optical absorbance with the concentration of SCG extracts. Figure 3 presents the calculated total phenolic content in the SCG extract solution. By analyzing the concentrations of the SCG extract solution alongside the gallic acid concentrations, the average total phenolic content as $9.44 \pm 0.90 \mathrm{mg}$ GAE/g SCG was calculated. The comparative total phenolic contents obtained in the present and previous studies using various methods are shown in Table 2.

3.4. Reduction Capacity Assay. This assay employed vitamin $\mathrm{C}$ with various concentrations as the standard. The results demonstrated that the SCG extracts increased its optical absorbance with concentration, indicating an increase in a reduced capacity. Substituting the optical absorbance readings into the vitamin $\mathrm{C}$ standard calibration curve yielded the reduction capacity results of the SCG extract solution shown in Figure 4. By analyzing the SCG extract solution concentrations alongside the vitamin C concentrations, this study calculated the average reduction capacity of the SCG as $8.18 \pm 0.39 \mathrm{mg}$ VCE/g SCG.

3.5. DPPH Free-Radical Scavenging Activity Assay. Half-maximal inhibitory concentration $\left(\mathrm{IC}_{50}\right.$ ) refers to the concentration of the extracts required to scavenge $50 \%$ of the DPPH-free radicals. Figure 5 presents the SCG extract solution's DPPH free-radical scavenging activity results. It reveals that the activity increased with the concentration of the solution and yielded an $\mathrm{IC}_{50}$ value of $3.11 \mathrm{mg} \mathrm{SCG} / \mathrm{mL}$, indicating that the SCG exhibited a certain level of DPPH free-radical scavenging activity. 


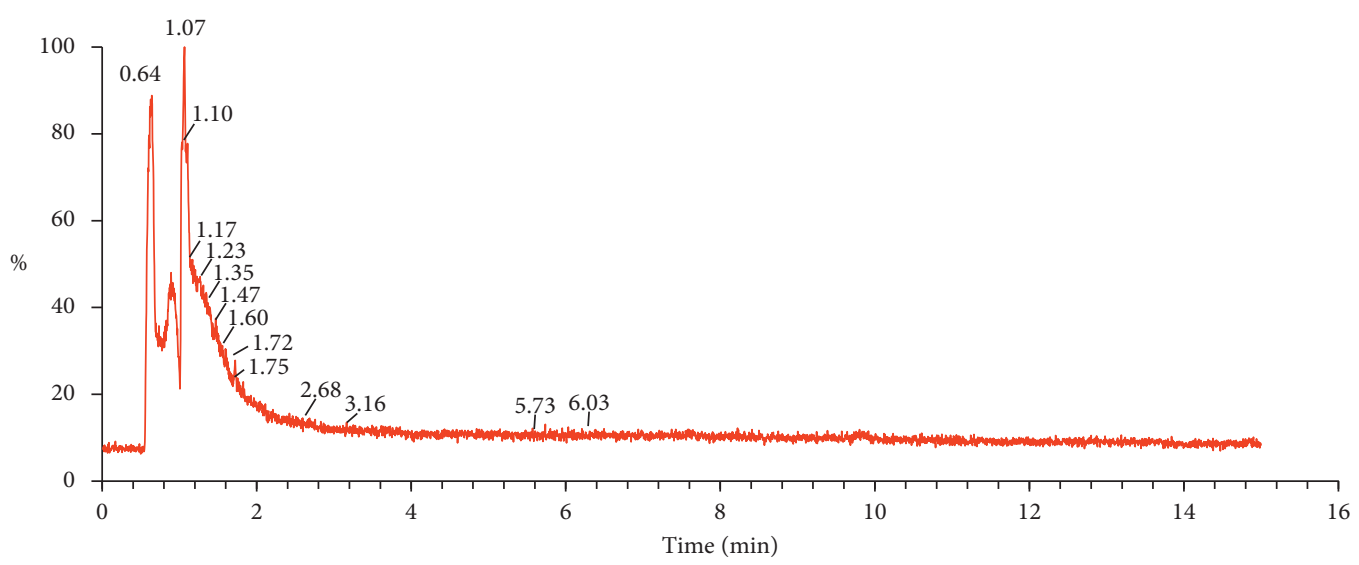

(a)

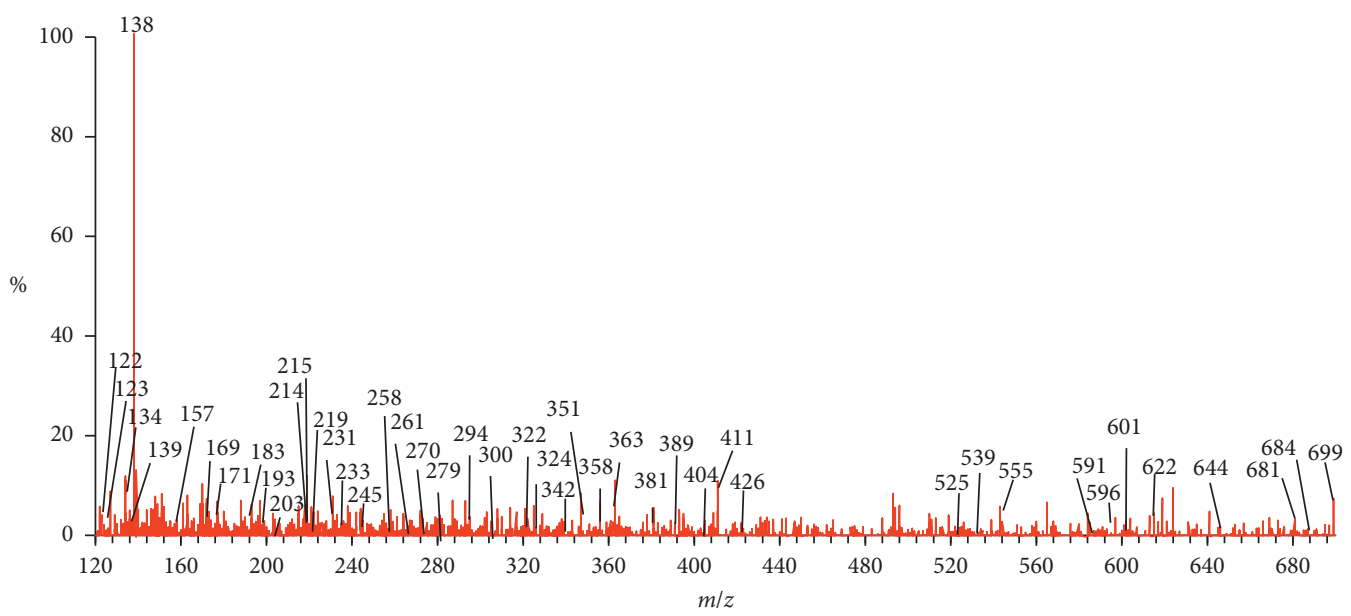

(b)

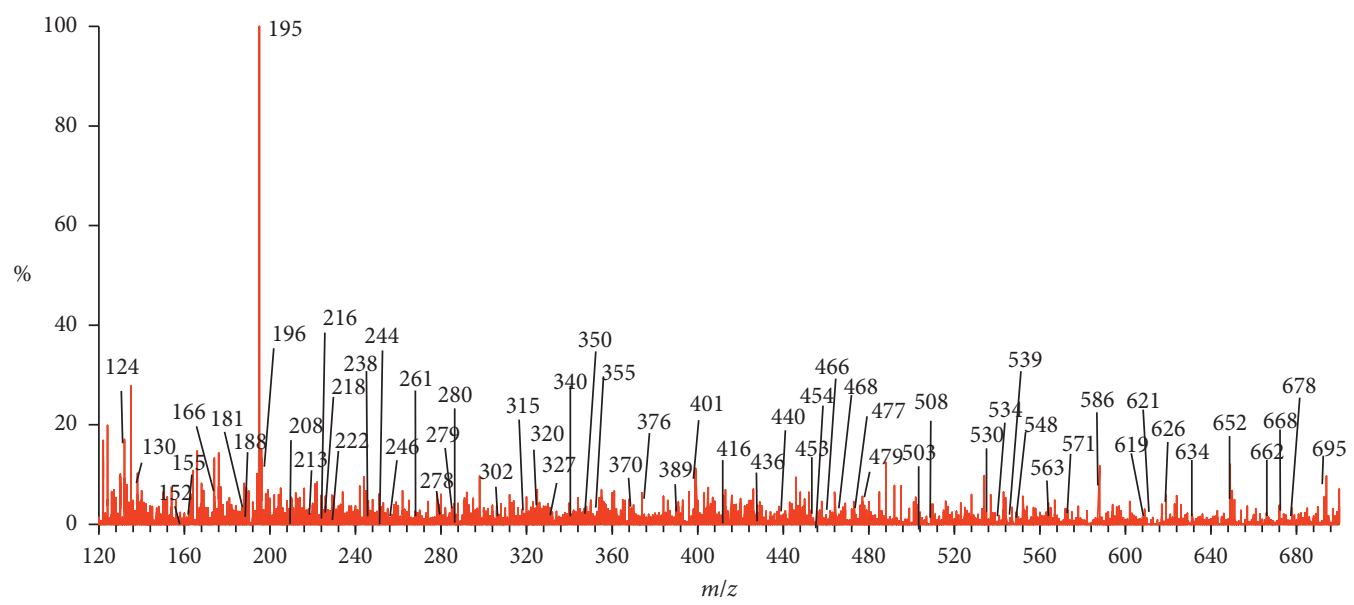

(c)

FIGURE 1: (a) LC-MS/MS chromatogram of the SCG extract solution. Mass spectrum of (b) trigonelline and (c) caffeine in the SCG extract solution.

Table 3 lists the $\mathrm{IC}_{50}$ values of DPPH scavenging for SCG obtained in various methods. Compared with the SCG obtained using $60 \%$ ethanol or water [20], the present study obtained a relatively low $\mathrm{IC}_{50}$ value by using the hydrothermal method (approximately $0.31 \% \mathrm{v} / \mathrm{v}$ ), indicating that the present study achieved favorable DPPH free-radical scavenging activity.
3.6. ABTS Free-Radical Scavenging Activity Assay. Figure 6 presents the ABTS free-radical scavenging activity of the SCG extracts. The activity increased with the concentration of the extracts, yielding an $\mathrm{IC}_{50}$ value of $13.61 \mathrm{mg}$ SCG $/ \mathrm{mL}$. This result indicated that the SCG exhibited a certain level of ABTS free-radical scavenging activity. 


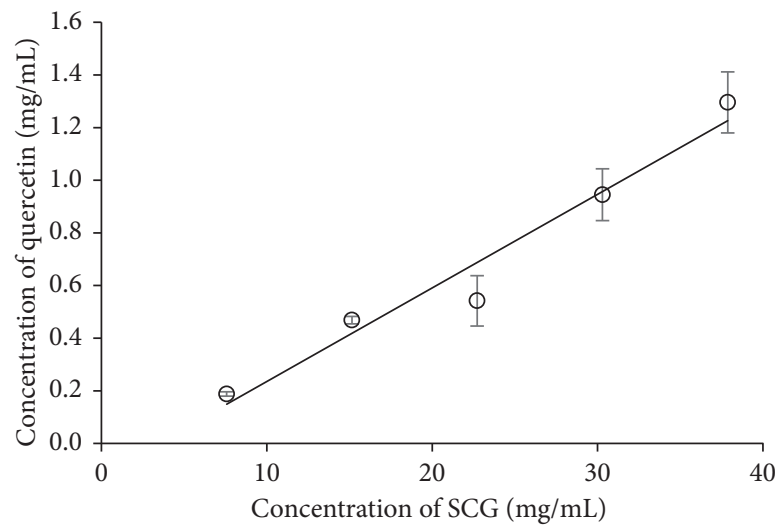

Figure 2: Total flavonoid content by quercetin equivalents versus SCG extract solution concentration.

TABLE 1: Comparative total flavonoid contents in SCG obtained by using various extraction methods.

Extraction conditions Total flavonoid content (mg QE/g SCG)

References

Hydrothermal method $\left(5 \mathrm{~g} \mathrm{SCG} / 35 \mathrm{~mL}, 150^{\circ} \mathrm{C}, 3 \mathrm{~h}\right.$ ) $29 \pm 4.5$

8.29

1.81

Present study

Hydrothermal method ( $\left.1 \mathrm{~g} \mathrm{SCG} / 20 \mathrm{~mL}, 120^{\circ} \mathrm{C}, 20 \mathrm{~min}\right)$

$60 \%$ methanol (1 g SCG/40 mL, $90 \mathrm{~min}$ )

$5.01 \sim 8.03$

[19]

$60 \%$ ethanol ( $\left.2 \mathrm{~g} \mathrm{SCG} / 100 \mathrm{~mL}, 60^{\circ} \mathrm{C}, 30 \mathrm{~min}\right)$

5.04

Ultrasound-assisted extraction (1 g SCG/17 mL ethanol, $40^{\circ} \mathrm{C}, 40 \mathrm{~min}$ )

[21]

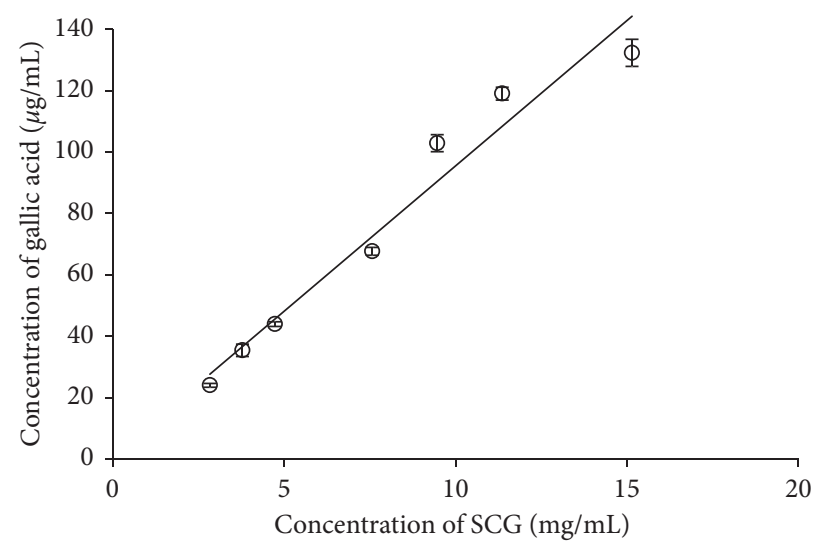

FIgURE 3: Total phenolic content by gallic acid equivalents versus SCG extract solution concentration.

TABLE 2: Total phenolic contents in SCG obtained using various methods.

\begin{tabular}{lcc}
\hline Extraction conditions & Total phenolic content $(\mathrm{mg}$ GAE/g SCG) & References \\
\hline Hydrothermal method $\left(5 \mathrm{~g} \mathrm{SCG} / 35 \mathrm{~mL}, 150^{\circ} \mathrm{C}, 3 \mathrm{~h}\right)$ & $9.44 \pm 0.90$ & Present study \\
Hydrothermal method $\left(1 \mathrm{~g} \mathrm{SCG} / 20 \mathrm{~mL}, 120^{\circ} \mathrm{C}, 20 \mathrm{~min}\right)$ & 32.92 & {$[19]$} \\
Hydrothermal method $\left(6 \mathrm{~g} \mathrm{SCG} / 160 \mathrm{~mL}, 180 \sim 240^{\circ} \mathrm{C}\right)$ & $33.1 \sim 51.2$ & 40.36 \\
Hydrothermal method $\left(1 \mathrm{~g} \mathrm{SCG} / 15 \mathrm{~mL}, 200^{\circ} \mathrm{C}, 50 \mathrm{~min}\right)$ & 16 & {$[22]$} \\
$60 \%$ methanol $(1 \mathrm{~g} \mathrm{SCG} / 40 \mathrm{~mL}, 90 \mathrm{~min})$ & $6.33 \sim 19.62$ & 17.44 \\
Water $\left(2 \mathrm{~g} \mathrm{SCG} / 100 \mathrm{~mL}, 60^{\circ} \mathrm{C}, 30 \mathrm{~min}\right)$ & $19 \sim 26$ & {$[1]$} \\
Water $\left(24 \mathrm{~g} \mathrm{SCG} / 400 \mathrm{~mL}, 80^{\circ} \mathrm{C}, 10 \mathrm{~min}\right)$ & 33.84 & {$[24]$} \\
Pressurized liquid $\left(70 \%\right.$ ethanol, $\left.195^{\circ} \mathrm{C}, 10 \mathrm{~min}\right)$ & {$[25]$} \\
Ultrasound-assisted extraction $(1 \mathrm{~g} \mathrm{SCG} / 17 \mathrm{~mL}$ ethanol, & & {$[21]$} \\
$40^{\circ} \mathrm{C}, 40$ min) & &
\end{tabular}




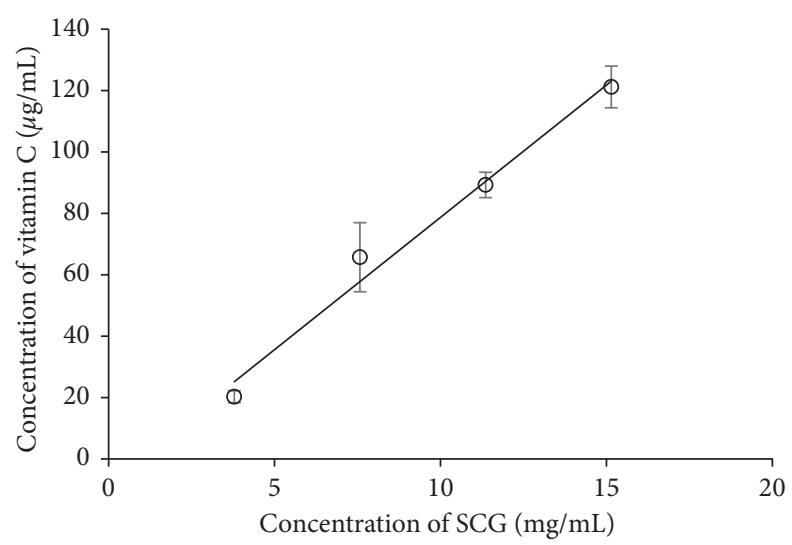

FIGURE 4: Reduction capacity by vitamin C equivalents versus SCG extract concentration.

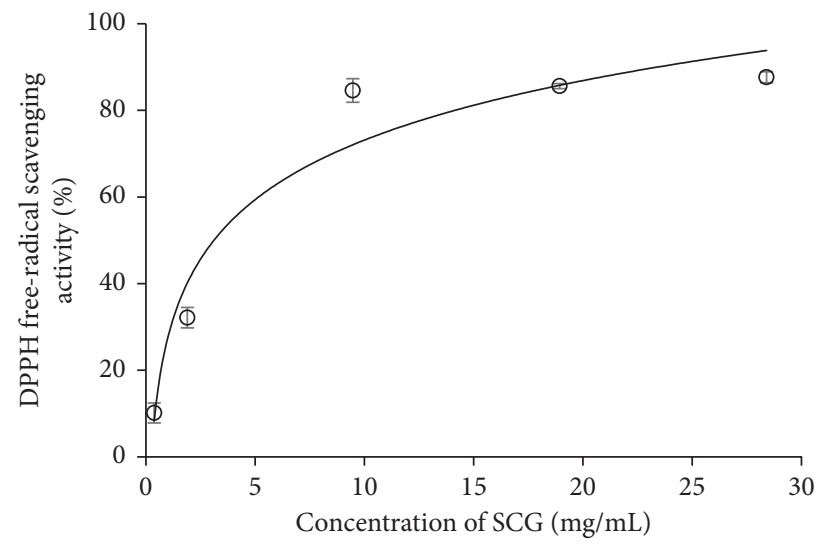

FIGURE 5: DPPH free-radical scavenging activity versus SCG extract solution concentration.

TABLE 3: $\mathrm{IC}_{50}$ values of DPPH scavenging for SCG.

\begin{tabular}{lcc}
\hline Extraction conditions & DPPH free-radical scavenging activity $\left(\mathrm{IC}_{50}, \% \mathrm{v} / \mathrm{v}\right)$ & References \\
\hline Hydrothermal method $\left(5 \mathrm{~g} \mathrm{SCG} / 35 \mathrm{~mL}, 150^{\circ} \mathrm{C}, 3 \mathrm{~h}\right)$ & 0.31 & Present study \\
$60 \%$ ethanol $\left(2 \mathrm{~g} \mathrm{SCG} / 100 \mathrm{~mL}, 60^{\circ} \mathrm{C}, 30 \mathrm{~min}\right)$ & $1.47 \sim 3.67$ & {$[20]$} \\
Water $\left(2 \mathrm{~g} \mathrm{SCG} / 100 \mathrm{~mL}, 60^{\circ} \mathrm{C}, 30 \mathrm{~min}\right)$ & $2.33 \sim 6.74$ & {$[20]$} \\
\hline
\end{tabular}

3.7. Tyrosinase Inhibition Capacity. The L-Dopa became black dopachrome after reacting with tyrosinase. This assay used kojic acid as the standard to inhibit tyrosinase activity and generate black dopachrome following the reaction with tyrosinase. Figure 7 presents the tyrosinase activity inhibition of the SCG and shows that as the SCG solution concentration increased, the level of tyrosinase activity inhibition gradually increased to between $50 \%$ and $70 \%$. The $\mathrm{IC}_{50}$ value of the SCG was $2.23 \mathrm{mg}$ SCG $/ \mathrm{mL}$, indicating that the SCG achieved a certain level of tyrosinase inhibition.

3.8. Moisturizing Ability. In this assay, the volatilization rates of DI water, $5 \%$ glycerine, $10 \%$ glycerine, and the SCG extract solution ( $37 \mathrm{mg} \mathrm{SCG} / \mathrm{mL}$ ) were compared to investigate their moisturizing abilities. Figure 8 compares the volatilization rates of these four substances and reveals that DI water had the highest volatilization rate [26]; 5\% glycerine, $10 \%$ glycerine, and the SCG extract solution all had relatively low volatilization rates, implying that glycerine and the SCG extract solution exhibited effective moisturizing ability. The volatilization rate of the SCG extract solution lie between those of $5 \%$ and $10 \%$ glycerine and was $15.9 \%$ lower than that of DI water.

The hydrothermal pretreatment under mild conditions was demonstrated to be an efficient method to recover antioxidant polyphenols from coffee residues [19]. In a different research, hydrothermal extraction was effectively used for the separation of antioxidant compounds from green coffee beans, and the effluent extracts were indicated to be suitable for food products [27]. In contrast to previous reports, in the present study, LC-MS/MS analysis of SCG extracts showed that trigonelline and caffeine were two major components. Total flavonoid content in the SCG extracts by using the modified hydrothermal method in the present study $(29 \pm 4.5 \mathrm{mg}$ QE/g SCG) was significantly higher than the previous reports. Also, in comparison to the pervious reports, the present study by changing the 


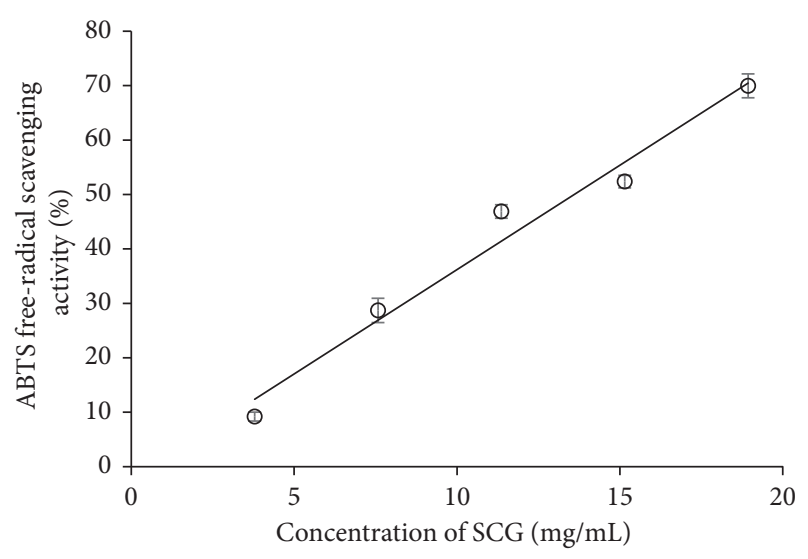

FIGURE 6: ABTS free-radical scavenging activity versus SCG extract solution concentration.

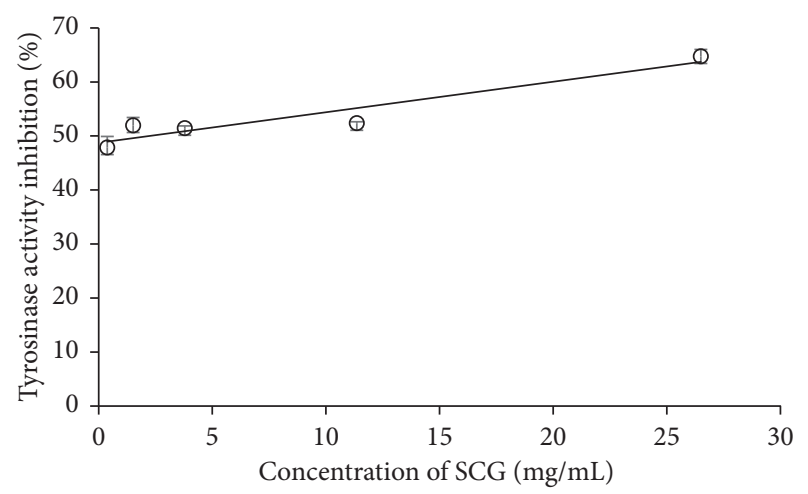

FIGURE 7: Tyrosinase activity inhibition versus SCG extract solution concentration.

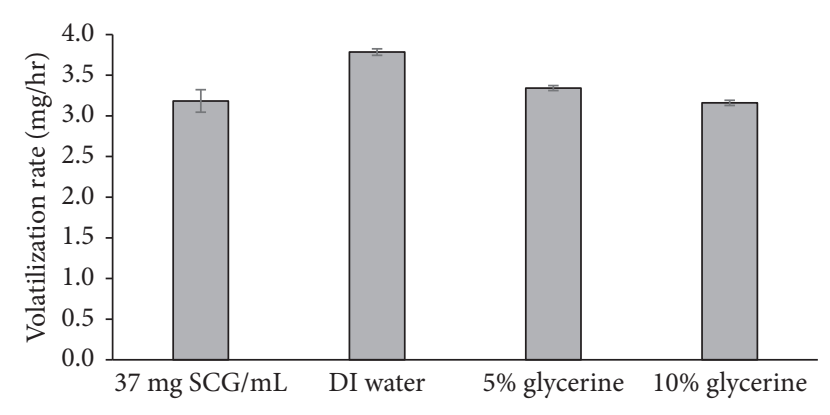

Figure 8: Volatilization rates of various samples.

extraction conditions achieved favorable DPPH free-radical scavenging activity $\left(\mathrm{IC}_{50}=0.31 \% \mathrm{v} / \mathrm{v}\right)$. In addition, we studied total phenolic content, reduction capacity, ABTS free-radical scavenging activity, tyrosinase inhibition capacity, and moisturizing ability of SCG extracts with a view of potential application of SCG in cosmetics and personal care.

\section{Conclusions}

In the present study, functionalities of spent coffee grounds (SCGs) were analyzed with a view of its reuse. The SCG extraction was carried out by the hydrothermal method. LCMS/MS results showed trigonelline and caffeine as two major components in SCG extracts. The extracts exhibited significant free-radical scavenging activity, ABTS free-radical scavenging activity, and tyrosinase inhibition capacity. Also, the volatilization rate of the extract solution was reduced by $15.9 \%$. The results obtained in the study demonstrate the utility of recycling of SCG. The hydrothermal method used in the study for SCG extraction will be a desirable method in the growing cosmetics and personal care market because being eco-friendly is a crucial factor for increasing customer satisfaction. Also, the study demonstrates the potential application of SCG in the development of skin care products.

\section{Data Availability}

The data used to support this study are included within the article.

\section{Conflicts of Interest}

The authors declare no conflicts of interest regarding the publication of this article.

\section{Acknowledgments}

This research was funded by the National United University (108-NUUPRJ-05) and the Ministry of Science and Technology, Taiwan.

\section{References}

[1] S. I. Mussatto, L. F. Ballesteros, S. Martins, and J. A. Teixeira, "Extraction of antioxidant phenolic compounds from spent coffee grounds," Separation and Purification Technology, vol. 83, pp. 173-179, 2011.

[2] S. I. Mussatto, L. M. Carneiro, J. P. A. Silva, I. C. Roberto, and J. A. Teixeira, "A study on chemical constituents and sugars extraction from spent coffee grounds," Carbohydrate Polymers, vol. 83, no. 2, pp. 368-374, 2011.

[3] N. Kondamudi, S. K. Mohapatra, and M. Misra, "Spent coffee grounds as a versatile source of green energy," Journal of Agricultural and Food Chemistry, vol. 56, no. 24, pp. 1175711760, 2008.

[4] S. Petrik, S. Obruča, P. Benešová, and I. Márová, "Bioconversion of spent coffee grounds into carotenoids and other valuable metabolites by selected red yeast strains," Biochemical Engineering Journal, vol. 90, pp. 307-315, 2014.

[5] A. S. Franca, L. S. Oliveira, A. A. Nunes, and C. C. O. Alves, "Microwave assisted thermal treatment of defective coffee beans press cake for the production of adsorbents," Bioresource Technology, vol. 101, no. 3, pp. 1068-1074, 2010.

[6] K. Ramalakshmi, L. J. M. Rao, Y. Takano-Ishikawa, and M. Goto, "Bioactivities of low-grade green coffee and spent coffee in different in vitro model systems," Food Chemistry, vol. 115, no. 1, pp. 79-85, 2009.

[7] P. S. Murthy and M. M. Naidu, "Recovery of phenolic antioxidants and functional compounds from coffee industry by-products," Food and Bioprocess Technology, vol. 5, no. 3, pp. 897-903, 2012. 
[8] K. Belguidoum, H. Amira-Guebailia, Y. Boulmokh, and O. Houache, "HPLC coupled to UV-vis detection for quantitative determination of phenolic compounds and caffeine in different brands of coffee in the Algerian market," Journal of the Taiwan Institute of Chemical Engineers, vol. 45, no. 4, pp. 1314-1320, 2014.

[9] K.-S. Lee and K.-S. Park, "A study of effects of coffee waste extracts obtained from solvents," The Korean Journal of Food and Nutrition, vol. 28, no. 5, pp. 866-870, 2015.

[10] M. Ranic, M. Nikolic, M. Pavlovic, A. Buntic, S. Siler-Marinkovic, and S. Dimitrijevic-Brankovic, "Optimization of microwave-assisted extraction of natural antioxidants from spent espresso coffee grounds by response surface methodology," Journal of Cleaner Production, vol. 80, pp. 69-79, 2014.

[11] P. Wu, G. Ma, N. Li, Q. Deng, Y. Yin, and R. Huang, "Investigation of in vitro and in vivo antioxidant activities of flavonoids rich extract from the berries of Rhodomyrtus tomentosa(Ait.) Hassk," Food Chemistry, vol. 173, pp. 194202, 2015.

[12] W. Y. Huang, Y. R. Lin, R. F. Ho, H. Y. Liu, and Y. S. Lin, "Effects of water solutions on extracting green tea leaves," Scientific World Journal, vol. 2013, Article ID 368350, 6 pages, 2013.

[13] J. P. Adjimani and P. Asare, "Antioxidant and free radical scavenging activity of iron chelators," Toxicology Reports, vol. 2, pp. 721-728, 2015.

[14] C.-C. Tsai, C.-F. Chan, W.-Y. Huang et al., "Applications of Lactobacillus rhamnosus spent culture supernatant in cosmetic antioxidation, whitening and moisture retention applications," Molecules, vol. 18, no. 11, pp. 14161-14171, 2013.

[15] W.-Y. Huang, P.-C. Lee, J.-C. Hsu, Y.-R. Lin, H.-J. Chen, and Y.-S. Lin, "Effects of water quality on dissolution of Yerba mate extract powders," Scientific World Journal, vol. 2014, Article ID 768742, 6 pages, 2014.

[16] C.-F. Chan, C.-T. Wu, W.-Y. Huang et al., "Antioxidation and melanogenesis inhibition of various Dendrobium tosaense extracts," Molecules, vol. 23, no. 7, pp. 1810-1820, 2018.

[17] H. Li, J. Xu, Y. Liu et al., "Antioxidant and moisture-retention activities of the polysaccharide from Nostoc commune," Carbohydrate Polymers, vol. 83, no. 4, pp. 1821-1827, 2011.

[18] D. J. O'Driscoll, "Analysis of coffee bean extracts by use of ultra-performance liquid chromatography coupled to quadrupole time-of-flight mass spectrometry," MethodsX, vol. 1, pp. 264-268, 2014.

[19] T. Conde and S. I. Mussatto, "Isolation of polyphenols from spent coffee grounds and silverskin by mild hydrothermal pretreatment," Preparative Biochemistry and Biotechnology, vol. 46, no. 4, pp. 406-409, 2016.

[20] A. Panusa, A. Zuorro, R. Lavecchia, G. Marrosu, and R. Petrucci, "Recovery of natural antioxidants from spent coffee grounds," Journal of Agricultural and Food Chemistry, vol. 61, no. 17, pp. 4162-4168, 2013.

[21] N. A. Al-Dhabi, K. Ponmurugan, and P. M. Jeganathan, "Development and validation of ultrasound-assisted solidliquid extraction of phenolic compounds from waste spent coffee grounds," Ultrasonics Sonochemistry, vol. 34, pp. 206213, 2017.

[22] A. T. Getachew and B. S. Chun, "Influence of pretreatment and modifiers on subcritical water liquefaction of spent coffee grounds: a green waste valorization approach," Journal of Cleaner Production, vol. 142, pp. 3719-3727, 2017.

[23] L. F. Ballesteros, M. J. Ramirez, C. E. Orrego, J. A. Teixeira, and S. I. Mussatto, "Optimization of autohydrolysis conditions to extract antioxidant phenolic compounds from spent coffee grounds," Journal of Food Engineering, vol. 199, pp. 1-8, 2017.

[24] J. Bravo, C. Monente, I. Juániz, M. P. De Peña, and C. Cid, "Influence of extraction process on antioxidant capacity of spent coffee," Food Research International, vol. 50, no. 2, pp. 610-616, 2013.

[25] Y.-F. Shang, J.-L. Xu, W.-J. Lee, and B.-H. Um, "Antioxidative polyphenolics obtained from spent coffee grounds by pressurized liquid extraction," South African Journal of Botany, vol. 109, pp. 75-80, 2017.

[26] Y.-S. Lin and C.-Y. Chen, "A novel evaporation detection system using an impedance sensing chip," The Analyst, vol. 139, no. 22 , pp. 5781-5784, 2014.

[27] T. Sato, T. Takahata, T. Honma et al., "Hydrothermal extraction of antioxidant compounds from green coffee beans and decomposition kinetics of 3-o-caffeoylquinic acid," Industrial \& Engineering Chemistry Research, vol. 57, no. 22, pp. 7624-7632, 2018. 

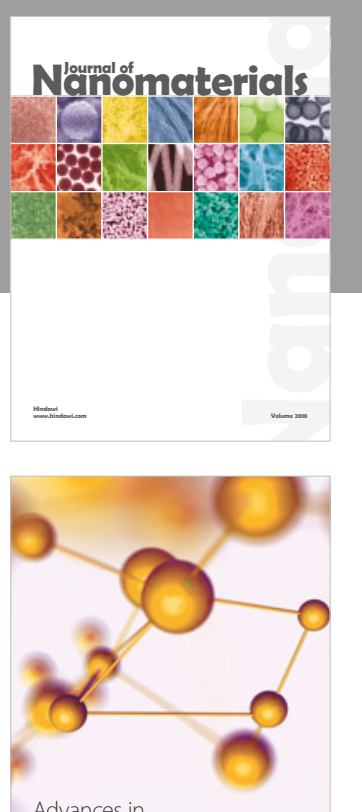

Physical Chemistry
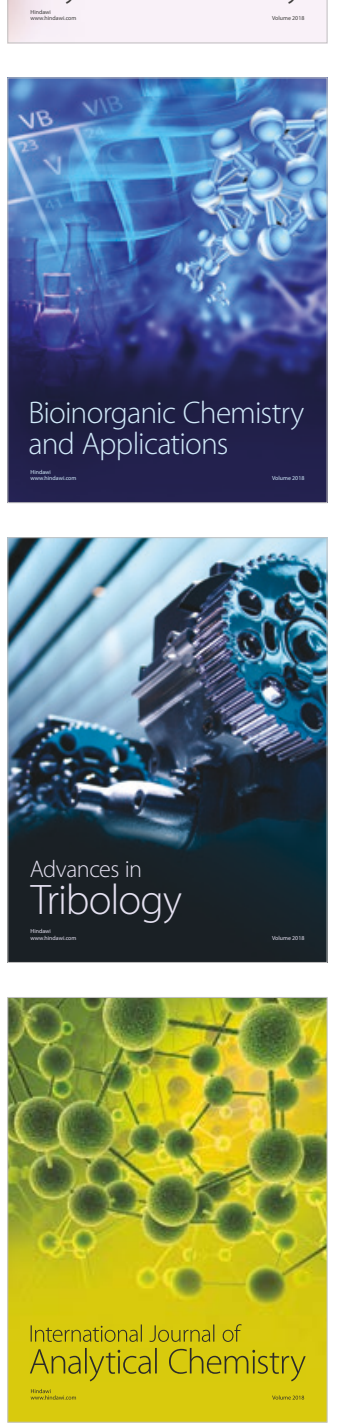

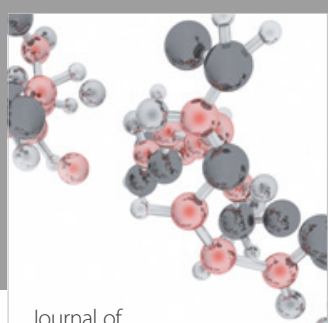

Analytical Methods

in Chemistry

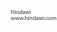

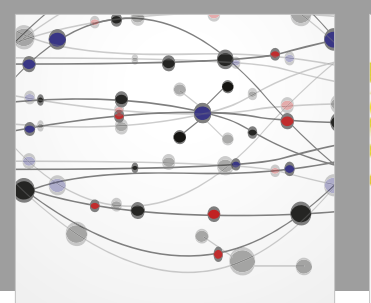

The Scientific World Journal

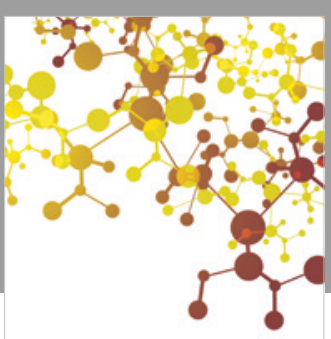

Journal of

Applied Chemistry
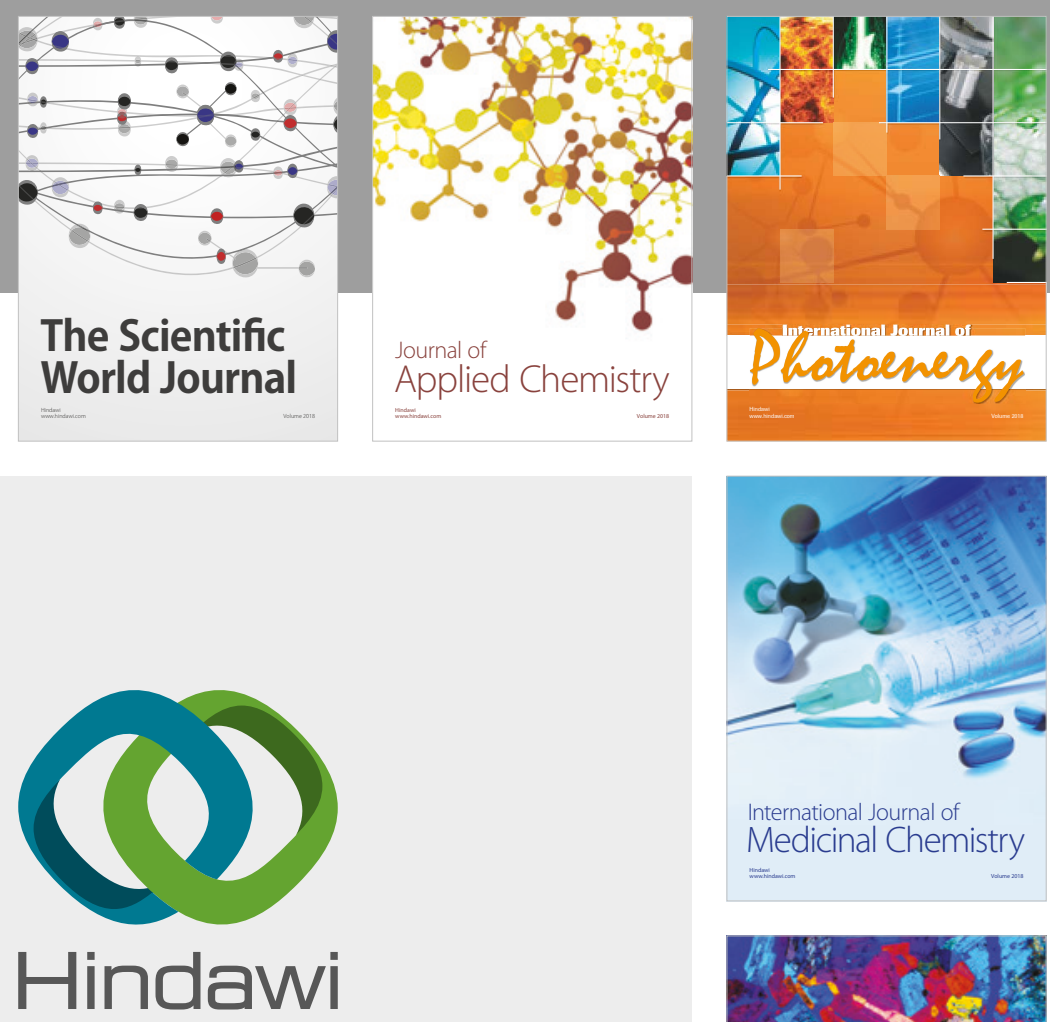

Submit your manuscripts at

www.hindawi.com
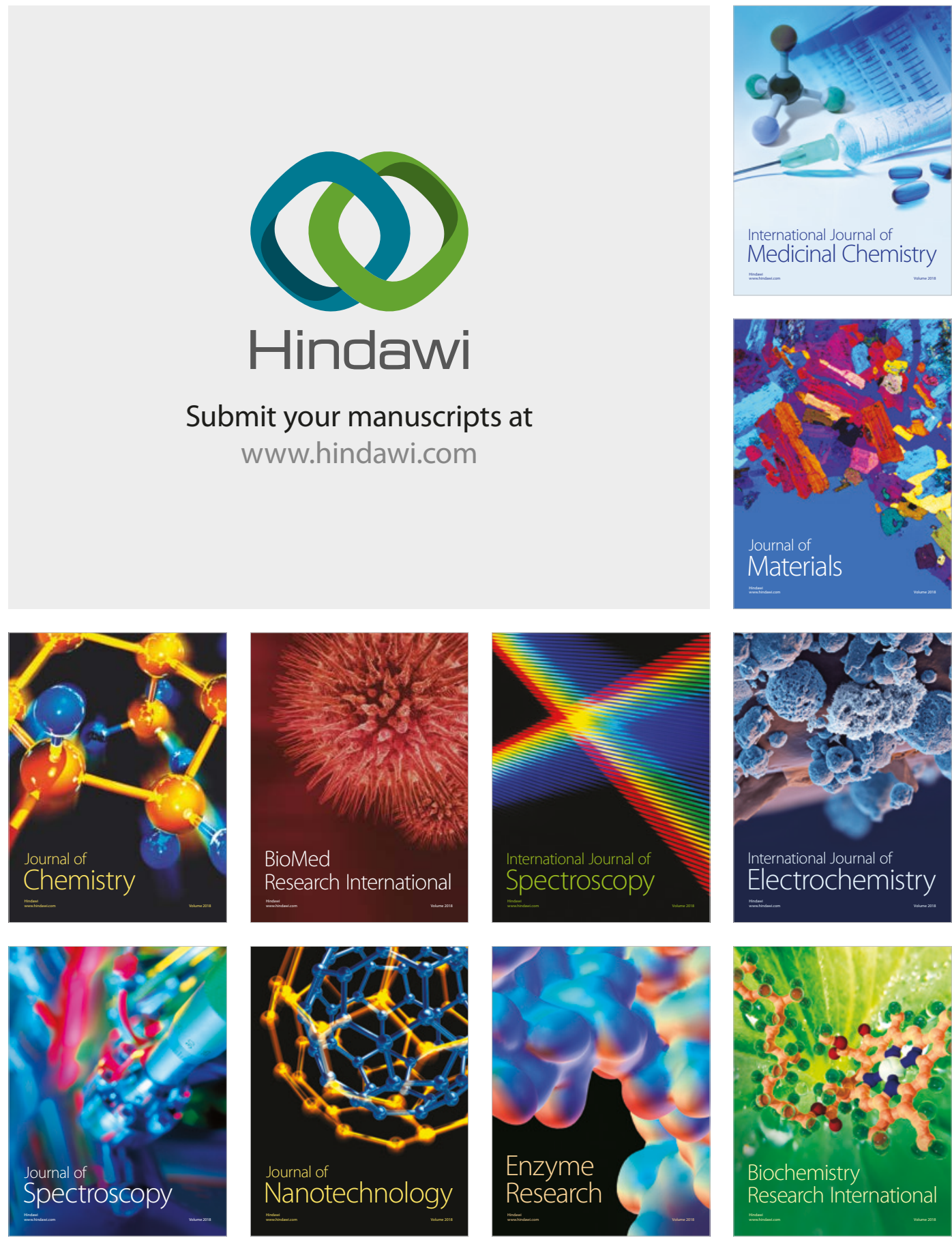
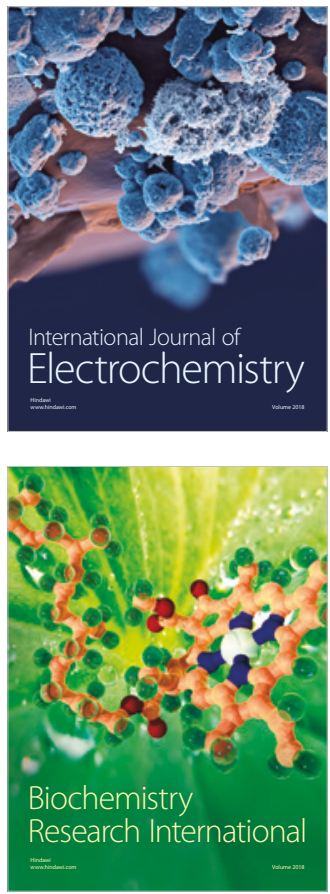